\title{
Effects of Helicobacter pylori Infection on the Histology, Cellular Phenotype, K-ras Mutations, and Cell Kinetics in Gastric Intestinal Metaplasia in Patients with Chronic Gastritis and Gastric Cancer
}

\author{
Jiro Watari et al.* \\ ${ }^{1}$ Division of Upper Gastroenterology, Department of Internal Medicine, Hyogo College of \\ Medicine, Nishinomiya, \\ Japan
}

\section{Introduction}

Helicobacter pylori (H. pylori) infection is a main risk factor for the development of gastric cancer (Correa et al., 1990; Sipponen \& Hyvarinen, 1993; International Agency for Research on Cancer [IARC], 1994; Graham, 2000; Uemura et al., 2001). It has been postulated that $H$. pylori infection causes chronic gastritis, gastric atrophy, usually with gastric intestinal mataplasia (GIM) and dysplasia, and gastric cancer. The stepwise fashion of this infection, which usually continues over decades, has been defined as a sequence of histological events that confer an increasing risk of malignant transformation as described in Correa's hypothesis (Correa \& Shiao, 1994). Although it is fairly well accepted that H. pylori infection plays a significant role in causing gastric cancer, the exact mechanisms involved in the pathogenesis remain obscure. In general, GIM is believed to be a preneoplastic lesion of the stomach (Correa, 1995), which increases the risk of gastric adenocarcinoma, especially intestinal type (Correa \& Shiao, 1994; Correa, 1988). It remains unclear, however, as to whether or not GIM is a precancerous lesion or a marker for an increased risk of malignancy (Filipe et al., 1994; Miehlke et al., 1998).

Although there are many reports regarding the histological changes including metaplasia and dysplasia following eradication of H. pylori, the results have been conflicting (Table 1 ).

\footnotetext{
${ }^{*}$ Hiroki Tanabe'2, Kentaro Moriichi², Mikihiro Fujiya ${ }^{2}$, Peter S. Amenta ${ }^{3}$, Hiroto Miwa ${ }^{1}$, Yutaka Kohgo ${ }^{2}$ and Kiron M. Das ${ }^{3}$

${ }^{1}$ Division of Upper Gastroenterology, Department of Internal Medicine, Hyogo College of Medicine, Nishinomiya, Japan;

${ }^{2}$ Division of Gastroenterology and Hematology/Oncology, Department of Medicine, Asahikawa Medical University, Asahikawa, Japan;

${ }^{3}$ Crohn's and Colitis Center of New Jersey, Division of Gastroenterology and Hepatology, Department of Medicine and Pathology, UMDNJ-Robert Wood Johnson Medical School, New Brunswick, NJ, USA
} 


\begin{tabular}{llc}
\hline \multicolumn{1}{c}{ Study } & \multicolumn{1}{c}{ Materials } & Follow-up period \\
\hline Improvement & & \\
Genta RM, et al. & Peptic ulcer $(\mathrm{n}=8)$ and others $(\mathrm{n}=3)$ & $1 \mathrm{yr}$ \\
Uemura N, et al. & Gastric cancer $(\mathrm{n}=65)$ & $6 \mathrm{mo}$ \\
Nardone G, et al. & Dyspepsia $(\mathrm{n}=45)$ & $1 \mathrm{yr}$ \\
Sung JJ, et al. & Volunteer $(\mathrm{n}=226)$ & $1 \mathrm{yr}$ \\
Ohkusa T, et al. & Dyspepsia $(\mathrm{n}=115)$ & $12-15 \mathrm{mo}$ \\
Kokkola A, et al. & Atrophic corpus gastritis $(\mathrm{n}=22)$ & $2.5 \mathrm{yr}$ \\
Correa P, et al. & Volunteer $(\mathrm{n}=226)$ & $72 \mathrm{mo}$ \\
Ley C, et al. & Volunteer $(\mathrm{n}=248)$ & $1 \mathrm{yr}$ \\
Mera R, et al. & Volunteer $(\mathrm{n}=394)$ & $12 \mathrm{yr}$ \\
You WC, et al. & Volunteer $(\mathrm{n}=3365)$ & $7 \mathrm{yr}$ \\
Unchanged & & \\
Witteman EM, et al. & Dyspepsia $(\mathrm{n}=23)$ & $1 \mathrm{yr}$ \\
Forbes GM, et al. & Duodenal ulcer $(\mathrm{n}=32)$ & $85 \mathrm{mo}$ \\
van der Hulst RW, et al. & Dyspepsia \& Peptic ulcer $(\mathrm{n}=106)$ & $1 \mathrm{yr}$ \\
Hibi K et al. & Gastric ulcer $(\mathrm{n}=16)$ & $6 \mathrm{mo}$ \\
& Duodenal ulcer $(\mathrm{n}=9)$ & \\
Satoh K, et al. & Atrophic gastritis $(\mathrm{n}=20)$ & $12-33 \mathrm{mo}$ \\
Tucci A, et al. & Fundic atrophic gastritis $(\mathrm{n}=20)$ & $3 \mathrm{yr}$ \\
Tepes B, et al. & Duodenal ulcer $(\mathrm{n}=63)$ & $4 \mathrm{yr}$ \\
El-Omar EM, et al. & Cancer patients' relatives $(\mathrm{n}=40)$ & $1 \mathrm{yr}$ \\
Kim N, et al. & Gastric ulcer $(\mathrm{n}=41)$ & $2 \mathrm{yr}$ \\
Kuipers EJ, et al. & Duodenal ulcer $(\mathrm{n}=72)$ & $2 \mathrm{yr}$ \\
Tanaka A, et al. & Reflux esophagitis $(\mathrm{n}=231)$ & $1 \mathrm{yr}$ \\
& Atrophic gastritis $(\mathrm{n}=39)$ & \\
\hline
\end{tabular}

Table 1. Summary of studies on changes of GIM scores after successful H. pylori eradication

Some reported that the histologic grade of GIM had improved after eradication (Genta et al., 1993; Uemura et al., 1997; Nardone et al., 1999; Sung et al., 2000; Ohkusa et al., 2001; Kokkola et al., 2002; Correa et al., 2000; Ley et al., 2004; Mera et al., 2005; You et al., 2006) but the others did not find any change (Witteman et al., 1995; Forbes et al., 1996; van der Hulst et al., 1997; Hibi et al., 1997; Satoh et al., 1998; Tucci A et al., 1998; Tepes et al., 1999; El-Omar et al., 2000 ; Kim et al., 2000 ; Kuipers et al., 2004 ; Tanaka et al., 2006). Some of the reasons for these discrepancies may be ethnic variations, completeness of eradication of the disease and the stage of the disease when treatment is initiated and short follow-up (most studies up to 1 year) (Kokkola et al., 2002; Forbes et al., 1996; Tucci A et al., 1998; Tepes et al., 1999; Kim et al., 2000; Tanaka et al., 2006). Uemura et al (Uemura et al, 1997) studied the changes of GIM after treatment of $H$. pylori in the patients with intramucosal gastric cancer who underwent endoscopic mucosal resection (EMR). In this study, they showed that GIM score regressed at 6 months after $H$. pylori eradication. To our knowledge, however, there are no studies about the long-term effects after $H$. pylori eradication on the difference of histologic changes of GIM between the patients with and without gastric neoplasms.

We developed a monoclonal antibody $\left(\mathrm{mAb}\right.$ ), Das- 1 (formerly known as $7 \mathrm{E}_{12} \mathrm{H}_{12}$, $\mathrm{IgM}$ isotype), that specifically reacts with colonic epithelium (Das et al. 1987). Using both 
immunoperoxidase and immunofluorescence assays, we and others have demonstrated that the antibody specifically reacts with colonic epithelium (both goblet and non-goblet absorptive cells), but not with enterocytes (including goblet cells) from jejunum or ileum and normal epithelium from the stomach and esophagus (Das et al. 1987; Halstensen et al., 1993). However, mAb Das-1 reacts sensitively (95\%) and specifically (100\%) to Barrett's epithelium (BE), a pre-neoplastic condition of the esophagus, and adenocarcinoma of the esophagus (Das et al. 1994; Griffel et al., 2000). These data support that BE is a "colonic" or "incomplete" type of intestinal metaplasia (Das et al. 1994). Although normal small intestinal epithelium does not react with mAb Das-1, small intestinal adenoma and adenocarcinoma strongly react with the antibody, suggesting a phenotypic change in the pre-cancerous state and in carcinoma (Onuma et al., 2001). We also reported that GIM of colonic phenotype, such as type II or type III (incomplete type) detected by the mucin histochemistry (Filipe \& Jass, 1986) and detected by mAb Das-1, is strongly associated with gastric cancer (Mirza et al., 2002). Ninety-three percent of GIM as well as gastric cancer from the same patients at a different area reacted with mAb Das-1, whereas GIM from patients without gastric cancer reacted less frequently $(35 \%)$ with the antibody $(\mathrm{p}<0.0001)$ (Mirza et al., 2002).

More recently, during screening a complimentary DNA library prepared from a human colon cancer cell line, T84, we isolated and cloned a novel human tropomyosin (hTM) isoform, termed TC22 (Lin et al. 2002). The amino acid sequence analysis of TC22 demonstrated that it is identical to normal colon epithelial tropomyosin isoform 5 (hTM5) except the C-terminal peptide aminoacids 222-247 coding exon 9. Using this C terminal peptide, we developed a mAb, termed TC22-4, which is specific to TC22 (Lin et al. 2002). The expression of TC22, identified by the TC22-4 mAb, progressively increased in benign adenomatous polyp of colon (35\%) and polyps with mild (57\%) and severe dysplasia (100\%) and in colon cancer (100\%) (Lin et al., 2002). hTMs are microfilament-associated proteins present in all eukaryotic cells with organ-specific isoforms and distinct functions (LeesMiller \& Helfman, 1991; Pittenger \& Helfman, 1992; Lin et al, 1997), and at least 8 isoforms of hTM are detected in human (Lin et al, 1997; Novy et al. 1993). hTM isoform 5 (hTM5) is the predominant isoform in normal colon epithelium and it acts as an autoantigen in ulcerative colitis (UC) (Das et al., 1993; Geng et al. 1998). We and others have shown that patients with UC demonstrate both humoral and cellular immune responses against hTM, particularly against isoform 5 (hTM5) (Das et al., 1993; Geng et al. 1998; Onuma et al., 2000; Biancone et al., 1995 ; Sakamaki et al., 2000 ; Taniguchi et al., 2001).

A K-ras mutation occurs relatively early in human carcinogenesis (Vogelstein et al., 1988), and it is detected in various types of human malignancies (Soh et al., 1993; Cooper 1995). Mutations of K-ras gene are found in $\sim 10 \%$ of intestinal-type gastric cancer but they are rarely detected in the diffuse type (Tahara, 1993; Arber et al., 2000; Hiyama et al., 2002). Furthermore, a K-ras mutation has been detected in preneoplastic lesions, such as mucous cell hyperplasia of the pancreas, which current term is pancreatic intraepithelial neoplasia, grade 1, suffering from chronic inflammation and regenerative or dysplastic epithelia of ulcerative colitis (Yanagisawa et al., 1993; Chaubert et al. 1994). However, there have been only a few reports of this oncogene in $\mathrm{H}$. pylori-associated chronic gastritis and GIM either with or without gastric cancer (Hiyama et al., 2002; Gong et al., 1999). Moreover, changes in K-ras mutations in GIM after H. pylori eradication have not yet been investigated.

In addition to genetic alterations, one of the pathways by which $H$. pylori is linked to gastric carcinogenesis may be related to the disruption in the balance between gastric epithelial cell 
proliferation and apoptosis as some investigators have reported (Moss et al., 1996; Wagner et al. 1997; Jones et al., 1997; Hoshi et al., 1999; Leung et al. 2001). However, such previous studies on the cell kinetics before and after $H$. pylori eradication have yielded conflicting results.

Epidemiological studies indicate that Asian countries have a high prevalence of $H$. pylori infection, with a correspondingly high incidence of gastric cancer. The annual incidence rate of gastric cancer per 100,000 population in various Asian countries, as reported by Parkin et al (Parkin et al., 1997), is very high in the northern parts of Asia, especially in Japan. In this paragraph, we illustrated around our previous studies (Watari et al., 2007; Watari et al., 2008) in the Japanese population, (i) if the eradication of $H$. pylori affects subsequent (over the course of up to 4 years) histological grade of GIM, (ii) if mAb Das-1 reactivity that identifies colonic phenotype of GIM associated with gastric carcinogenesis changes after eradication of H. pylori, and (iii) to assess the expression of the novel tropomyosin isoform TC22 in GIM before and after H. pylori treatment. p53 expression was also examined, in parallel. Additionally, we investigated (iv) if $H$. pylori eradication affects K-ras mutations and cell kinetics including cell proliferation and apoptosis in GIM.

\section{Patients and methods}

\subsection{Study 1}

Gastric biopsy samples (during 288 endoscopic procedures) from $96 \mathrm{H}$. pylori-positive Japanese patients were obtained prior to introduction of therapy, and, subsequently, over a follow-up period of up to 4 years. In all patients, biopsy specimens were taken to assess $H$. pylori infection, two from the greater curvature of the antrum and two from the greater curvature of the corpus of the stomach. H. pylori status was analyzed in each patient by two methods: Wartin-Starry staining and H. pylori culture. A patient was regarded as positive for $H$. pylori if at least one is positive, and the patient received anti-H. pylori therapy. All of the patients underwent upper endoscopy again after 2 to 3 months post-therapy to ensure successful eradication of $H$. pylori, and then were followed-up with yearly endoscopy, up to 4 years (mean 2.6 yrs, range; 1 to 4 ). At each endoscopy, successful eradication was documented by the above methods. None of the patients showed positive for H. pylori during the follow-up period.

\subsubsection{Histology and patient classification}

GIM was defined as replacement of the gastric epithelium by intestinal type epithelium, and was composed of two types; the presence of absorptive enterocytes with brush border along with goblet cells, or columnar cells with foamy cytoplasm, lacking brush border (Filipe et al., 1994).

In this study, the patients with chronic gastritis with gastric ulcers or gastroduodenal ulcers were included. Almost half of the patients (53.9\%) had gastric ulcers and the remainder had both gastric as well as duodenal ulcers (Take et al. 2005). The patients with duodenal ulcer only were excluded because most duodenal ulcers were categorized as antral predominat gastritis (Uemura et al., 2001) or non-atrophic gastritis (Mera et al. 2005), which has a low risk for gastric cancer and difference from gastric and gastroduodenal ulcers in pathophysiology (Uemura et al., 2001; Take et al. 2005).

The $96 \mathrm{H}$. pylori-positive patients were divided into 3 groups on the basis of history and initial histology by a single experienced pathologist (P.S.A.). Group CG $(n=36)$ had 
histologically chronic gastritis, but no GIM. This group was considered to correspond to non-metaplastic multifocal atrophic gastritis according to the global diagnosis by Mera et al (Mera et al. 2005). Thirty of the 36 patients had peptic ulcers, comprising 34 gastric ulcers and 2 gastroduodenal ulcers, and 6 patients had chronic gastritis without ulcer. Group IM consisted of patients with chronic gastritis with GIM $(n=33)$. Twenty-six patients had gastric ulcers and 7 patients had gastroduedenal ulcers. Group DYS consisted of patients with dysplasia $(n=27)$. This comprised low-grade dysplasia $(n=13)$, high grade-dysplasia $(n=13)$, and cancer with microinvasion to the submucosa $(n=1)$. All patients in Group DYS underwent EMR for dysplasia, and then received treatment for H. pylori.

Serial sections $(4 \mu \mathrm{m})$ were made and consecutive sections were used for histologic examination by H\&E staining, mucin stainings by alcian blue and high iron diamine, $\mathrm{pH} 2.5$ (AB/HID), and for immunohistochemistry, as described below. All slides were sent from Japan to NJ, USA, and evaluated and scored for GIM according to the updated Sydney system (Dixon et al., 1996; Rugge et al., 2000) by a single pathologist (P.S.A.) in NJ, who was unaware of the patient groups and treatment status. Scores were given numerically as follows: 0 for absence, and 1, 2, 3 for mild, moderate, or severe GIM. The GIM score was assessed in the samples obtained from the antrum, including patients with dysplasia at a different site of the stomach (Group DYS).

\subsubsection{Alcian blue ( $\mathrm{pH} 2.5) /$ High iron diamine (AB/HID) staining}

Serial sections were stained with AB/HID to identify neutral mucins, sialomucins, and sulphomucins using the standard method (Filipe et al., 1994). Briefly, slides were immersed in HID solution for 24 hours at room temperature. Slides were rinsed with distilled water, and then stained with $1 \%$ Alcian blue $(\mathrm{pH} 2.5)$ for 30 minutes. Three phenotypes of GIM were classified as described by Filipe and Jass (Filipe \& Jass, 1986) namely type I (complete or small intestinal type), types II \& III (incomplete or colonic type). When more than one type of GIM coexisted in a given sample, the case was classified according to the dominant type present in the section.

\subsubsection{Immnoperoxidase assays with mAb Das-1, TC22-4, and anti-p53}

Serial sections were stained with mAb Das-1 (mouse IgM mAb highly specific against Barrett's epithelium), TC22-4 (mouse IgG1 mAb against a novel tropomyosin isoform, TC22, specific for colon cancer) and anti-p53 monoclonal antibody, DO7 (mouse IgG 2b, Dako, Carpenteria, CA) using sensitive immnoperoxidase assays as described previously (Das et al., 1994; Mirza et al., 2003; Lin et al., 2002). Briefly, after deparaffinization and rehydration, free aldehydes were reduced with $0.05 \%$ sodium borohydride for $20 \mathrm{~min}$ at $4^{\circ} \mathrm{C}$. The tissue sections were treated with the antigen-retrieval technique for TC22 and p53 staining. They were then sequentially incubated with mAb Das-1, mAb TC22-4 and DO7 for 45 min at room temperature (for DO7), overnight at $4^{\circ} \mathrm{C}$ (for mAb Das-1), and $5 \mathrm{hr}$ at $4^{\circ} \mathrm{C}$ (for $\mathrm{mAb}$ TC22-4), followed by biotinylated rabbit antimouse IgM or IgG (Dako), 3\% hydrogen peroxide, and streptoavidin peroxidase (Dako). Subsequently, the slides were treated with diaminobenzidine- $\mathrm{H}_{2} \mathrm{O}_{2}$ solution for $20 \mathrm{~min}$ at room temperature. Each experiment included positive controls for $\mathrm{mAb}$ Das-1, normal colon section, and colon cancer tissue sections as positive controls for mAb TC22-4 and anti-p53 immunostainings. As negative controls, jejunum (for mAb Das-1) and normal colon (for TC22-4 and p53) were used. 


\subsection{Study 2}

We enrolled 64 patients with successful H. pylori treatment who had atrophic gastritis $(n=39)$ and intestinal-type mucosal gastric cancer after $\operatorname{EMR}(n=25)$. Following successful eradication, all patients were followed up by endoscopy for 1 year. All these patients histologically showed GIM in gastric biopsy samples both before and after H. pylori eradication. In order to improve the accuracy regarding the genetic alterations, the number of samples was increased. Twenty-eight intestinal-type early gastric cancer cases that had undergone a surgical resection were randomly selected from the histopathology files of Asahikawa Medical University Hospital during the same period and thus were added to this study.

Finally, the patients in this study included, Group IM (n=39): chronic gastritis cases with GIM, and Group DYS ( $n=53)$ : intestinal-type early gastric cancer, further divided into Group DYS-1 ( $n=25)$ : EMR cases diagnosed as mucosal cancer and Group DYS-2 $(n=28)$ : surgical resection cases, consisting of 10 mucosal cancers and 18 submucosal invasive cancers. All patients in Group DYS-1 underwent EMR for their mucosal cancer lesions, and thereafter received treatment for $H$. pylori.

\subsubsection{DNA preparation and detection of K-ras mutations}

Four tissue sections, each measuring $10 \mu \mathrm{m}$ in thickness, were serially cut from paraffin embedded tissue blocks. DNA was extracted from only GIM (Fig. 1). In this procedure of DNA extraction, the tissue specimens were precisely microdissected under microscopic visualization, using a PixCell laser capture microdissection system (Arcturus Engineering, Mountain View, CA) to avoid any DNA contamination of inflammatory or stromal cell nuclei. DNA was then extracted from the microdissected tissue specimen by proteinase $\mathrm{K}$ treatment, followed by phenol-chloroform extraction.
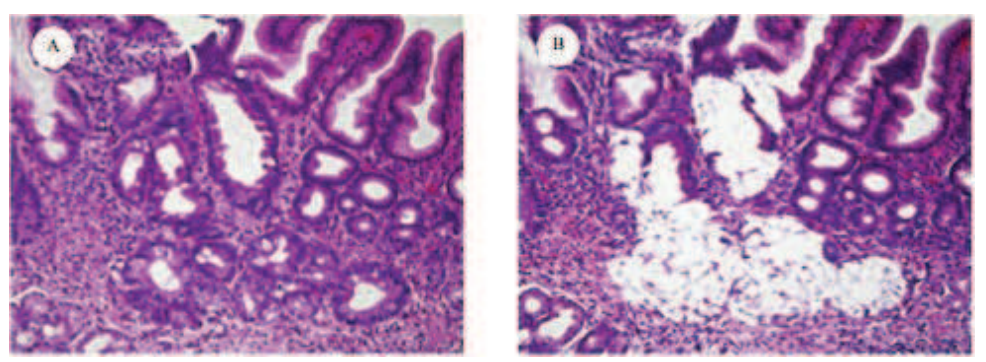

Fig. 1. Metaplastic glands were isolated by a laser capture microdissection. (A) H\&E stained section, (B) The same section, after the removal of metaplastic glands.

The detection of point mutations in codon 12 of the K-ras gene was performed by enriched polymerase chain reaction-restriction fragment length polymorphism (PCR-RFLP) as previously described with minor modifications (Levi et al., 1991; Sanger et al., 1997). The DNA from the K-ras sequence of exon 1 was amplified by a first PCR using the mismatched primers as previously described (Levi et al., 1991). After restriction enzyme digestion using Mval (Toyobo Company, Tokyo, Japan), PCR was performed in a $20 \mu$ l reaction mixture using Ampli-Taq Gold DNA polymerase (Perkin Elmer Applied Biosystems Division, Foster City, CA) according to the manufacturer's manual. In a second PCR and after another round of MvaI digestion, wild type fragments were cleaved to yield 29 and 106 base pair (bp) products, whereas mutant fragments yielded $135 \mathrm{bp}$. Electrophoresis of the digested sample 
on 3\% agarose gel confirmed the mutation band. SW480, a colon cancer cell line, and HT29 were used as a positive and negative control for K-ras codon 12, respectively (Fig. 2).

\subsubsection{Sequencing analysis}

The mutant fragments identified by enriched PCR-RFLP were confirmed by direct sequencing. The sequence of codon 12 was determined by automated fluorescent DNA sequencing using the dideoxy chain termination method (Sanger et al., 1997). PCR products were used for the cycle sequencing. The products were purified using Centricon-100 (Amicon Inc, Beverly, MA) following the manufacturer's protocol and then were sequenced using the Dye Terminator Cycle Sequencing Ready Reaction (Perkin Elmer Applied Biosystems Division, Foster City, CA) according to the manufacturer's instructions as reported previously (Watari et al., 2002). The sequencing reaction products were analyzed on ABI PRISM Geluxe ${ }^{\mathrm{TM}}$ (Perkin Elmer) on an ABI PRISM 310 DNA sequencer (Perkin Elmer).

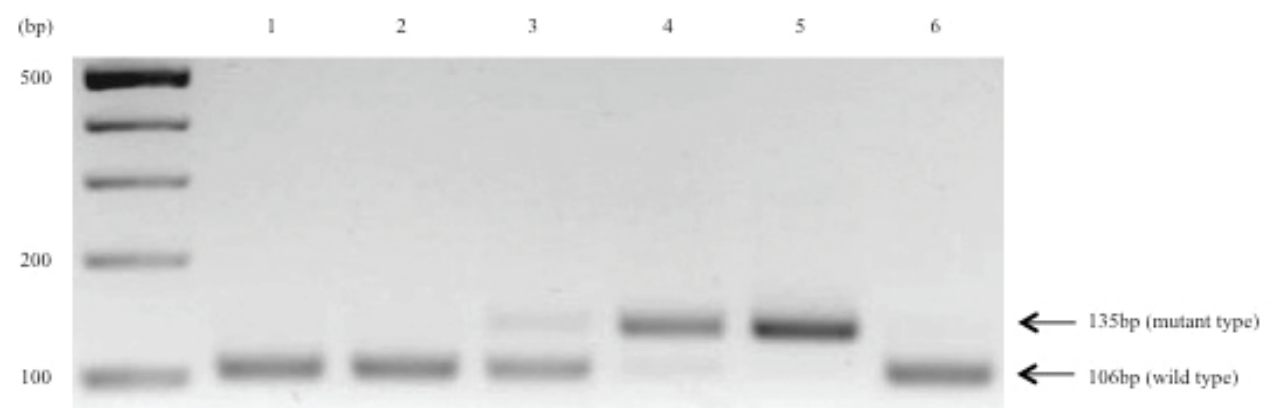

Fig. 2. A K-ras mutation in codon 12 was detected by enriched PCR-restriction fragment length polymorphism in gastric intestinal metaplasia (GIM) from patients with and without gastric cancer. The arrows indicate the positions of the mutant (135bp) and wild-type (106bp) bands. Lane 1: GIM from patient with gastric cancer; lanes 2-4: GIM from patients without gastric cancer; lane 5: SW480 as positive control; lane 6: HT29 as negative control.

\subsubsection{Detection of proliferation and apoptosis}

Dewaxed paraffin sections were examined by the avidin-biotin peroxidase complex (ABC, Vector Laboratories, Burlingame, CA) method using the primary antibody for Ki-67 antigen of proliferating cells (mouse IgG, Invitrogen, Calsbad, CA, USA). The slides were treated with the antigen-retrieval technique based on microwave oven heating.

Apoptotic cells in situ were detected by the terminal deoxynucleotidyl transferase-mediated dUTP nick-end labeling (TUNEL) method as previously described (Gavrieli et al., 1992). The slides were dewaxed and rehydrated through a graded alcohol series. The tissue specimens were digested with $20 \mu \mathrm{g} / \mathrm{ml}$ proteinase K (Boehringer, Mannheim, Germany) for $30 \mathrm{~min}$ at $37^{\circ} \mathrm{C}$. After treating with a $2 \% \mathrm{H}_{2} \mathrm{O}_{2}$ solution, the sections were preincubated with $100 \mathrm{mM}$ potassium cacodylate, $2 \mathrm{mM}$ cobalt chloride, $0.2 \mathrm{mM}$ dithiothreitol, $\mathrm{pH} 7.2$ for $3 \mathrm{~min}$, and then were incubated with the same buffer containing $0.3 \mathrm{U} / \mu 1$ terminal deoxynucleotidyl transferase (TdT, GIBCO BRL Gaithersburg, MD) and $0.04 \mathrm{nmol} / \mu$ l biotinylated dUTP (Boehringer, Mannheim, Germany) in a humid chamber at $37^{\circ} \mathrm{C}$ for $1 \mathrm{hr}$. The slides were 
rinsed in 30mM sodium citrate, $300 \mathrm{mM}$ sodium chloride for 30 minutes at RT, and washed in phosphate-buffered saline (PBS). After blocking with 10\% rabbit serum for $10 \mathrm{~min}$ and rinsing briefly in PBS, sections were incubated with ABC for $30 \mathrm{~min}$ at RT. Labeled cells were visualized with diaminobenzidine. The sections were then counterstained with hematoxylin. In GIM in each case, a minimum of 300 cells from some fields randomly selected were counted and the fractions (\%) of cells that showed positive nuclear staining for Ki-67 antigen (Fig. 3A) and TUNEL (Fig. 3B) were considered to be the proliferative indices (PI) and the apoptotic indices (AI), respectively. The PI and AI were determined independently by a single physician (J.W.).
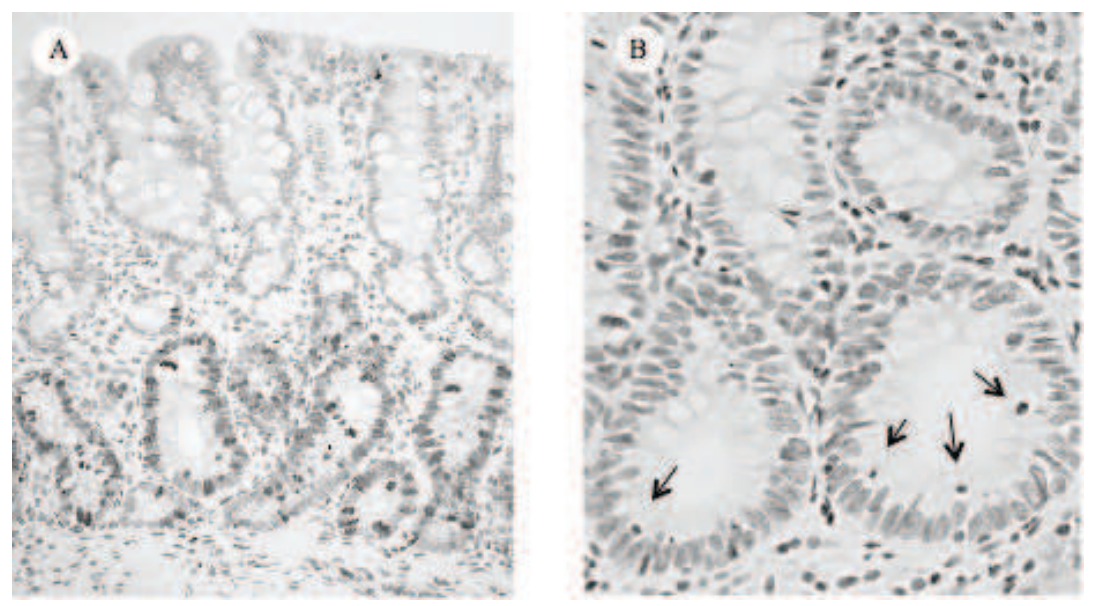

Fig. 3. Ki-67 staining and TUNEL in a representative case of gastric intestinal metaplasia (GIM). (A) Proliferating cells were found predominantly in the lower portion of GIM. (B) Apoptotic cells (arrows), detected by the TUNEL method were seen.

\subsection{Consent and ethical approval}

Regarding the above studied, written informed consent was obtained from the patients, and the Ethics Committee of Asahikawa Medical University gave their approval for this study.

\subsection{Statistical analysis}

All data are presented as means \pm SEM. Statistical analyses were assessed by the Student $t$ test, by Mann-Whitney $U$ test, by the Kruskal-Wallis test, by chi-square test and by Fisher's exact test. The Wilcoxon signed-rank test was used in the comparison of parameters before and after treatment in the same patient. Statistical significance was defined as $p<0.05$.

\section{Results}

\subsection{Study 1}

\subsubsection{Histologic score at initial diagnosis}

Patients in Group CG had evidence of chronic gastritis, but did not have GIM. At the initial diagnosis, GIM scores in Group DYS were significantly higher than those in Group IM $(\mathrm{p}<0.05)$ and Group CG $(\mathrm{p}<0.0001)$ (Fig. 4). 


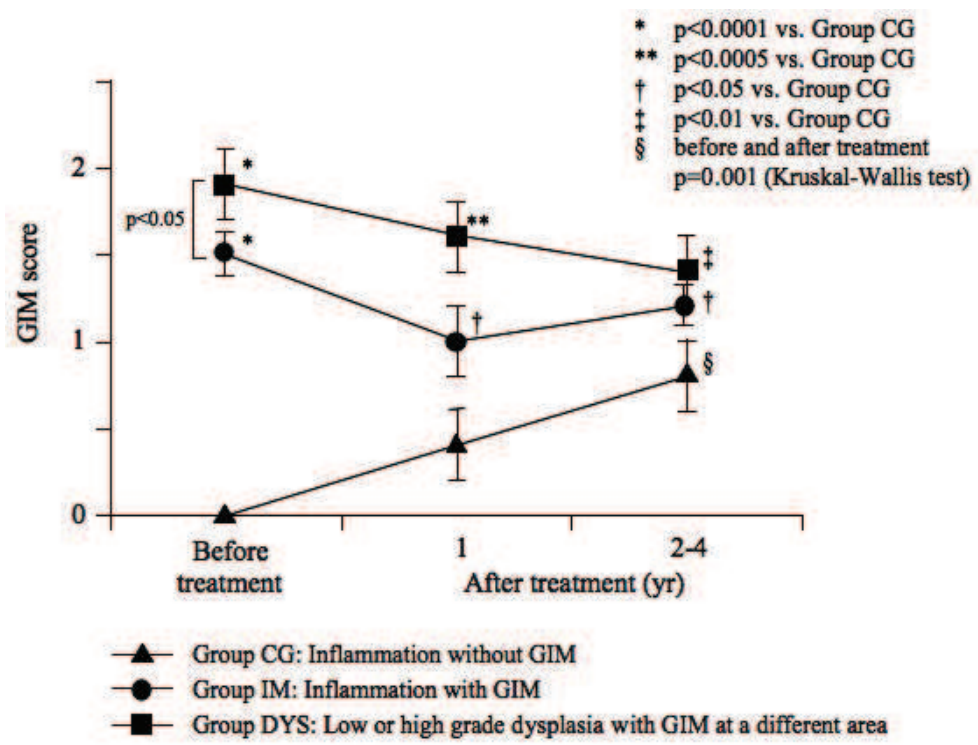

Fig. 4. Initial histologic GIM scores and changes in the score in patients followed up over 4 years after H. pylori eradication. GIM scores were significantly higher in Group DYS than in Group IM before eradication ( $\mathrm{p}<0.05)$. At initial stage, none of the patients in Group CG had GIM, although all had gastritis. GIM scores in Groups IM and DYS were higher than those in Group CG at 1 year after treatment ( $<<0.05$ and $p<0.0005$, respectively), as well as at 2 to 4 years. After eradication of $H$. pylori in both Groups IM and DYS there were slow minor declines of GIM scores that were not statistically significant. However, GIM score in patients from Group CG increased even if $H$. pylori was eliminated, and this difference was statistically significant ( $p=0.001$, Kruskal-Wallis test). The GIM score in Group CG was significantly lower than in Groups IM and DYS at the 1-year follow-up evaluation, as well as at the end of 4 years.

\subsubsection{Reactivity against mAb Das-1, TC22-4 and anti-p53 before treatment}

In Group CG, with chronic gastritis without GIM, there was no immunoreactivity with any of the gastric mucosal samples against mAb Das-1, TC22-4 and anti-p53 (Fig. 5). In Group IM patients, the immunoreactivity against mAb Das-1 was 39\% (13 of 33) and against TC224 it was $36 \%$ (12 of 33). The reactivity against anti-p53 was 3\% (1 of 33). The reactivity of $\mathrm{mAb}$ Das-1 is diffuse cytoplasmic with higher intensity at the periphery of cells and is present in both goblet cells and non-goblet cells in the GIM areas (Fig. 6E). The TC22 reactivity is seen as intracellular cytoplasmic dot-like staining in a punctate manner (Fig. $6 \mathrm{~F}$ ), and p53 staining is detected in scattered cells mainly in the nuclei of the glands (Fig. $6 \mathrm{~N})$. In patients from Group DYS, the reactivity of mAb Das-1, TC22-4 and anti-53 in GIM areas away from dysplastic areas was 63\% (17 of 27), 48\% (13 of 27) and 15\% (4 of 27), respectively. Twenty-four of 27 (89\%) of patients showed positive reactivity with mAb Das-1 at the dysplastic areas (Fig. 5). If the dysplastic area is positive with mAb Das-1, GIM areas away from the dysplastic areas of the same patients were also positive. Of the 13 patients who were positive with TC22-4 in the GIM areas, 11 of these $13(85 \%)$ patients' dysplastic areas also showed reactivity to TC22-4. The mAb Das-1 reactivity showed progressive 
increase between Group IM and Group DYS (Fig. 5). TC22 expression, although numerically higher in Group DYS than in Group IM (48\% vs. 36\%), was not statistically significant. However, in the same patients following eradication, as described below, there was a significant decline of immunoreactivity. p53 expression in the GIM areas in the 2 groups (IM and DYS) were $3 \%$ vs. $15 \%$ respectively. Anti-p53 reactivity was much higher in the dysplastic areas in Group DYS (59\%, 16 of 27) (Fig. 5).

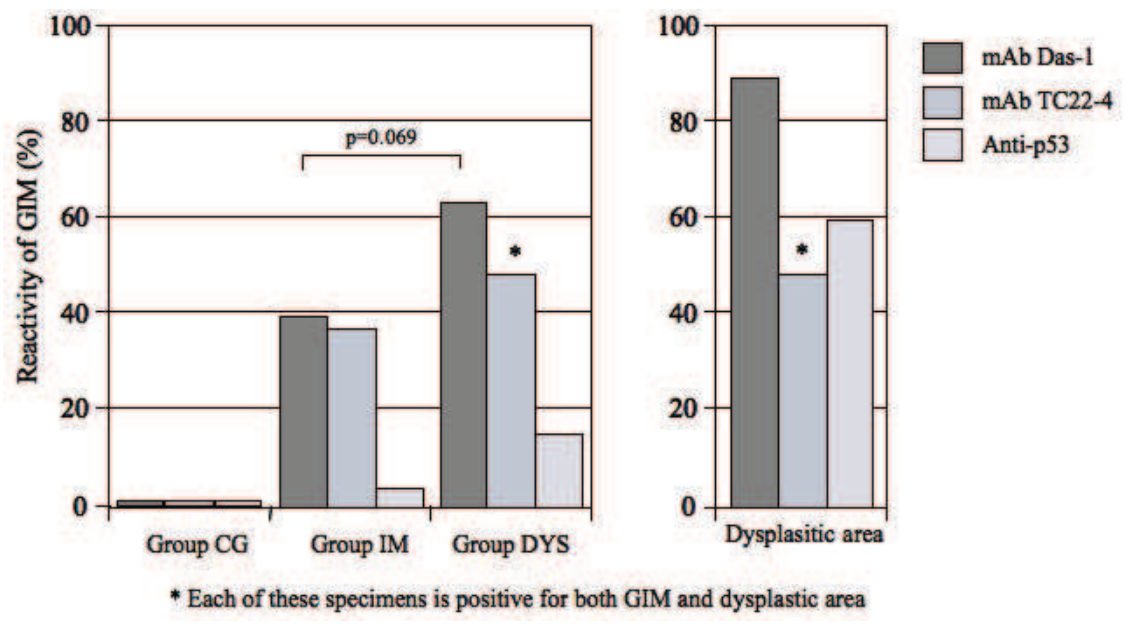

Fig. 5. Reactivity of GIM to mAb Das-1, TC22-4 and anti-p53 in patients from Groups CG, IM, and DYS before treatment. In Group CG, no reactivity to mAb Das-1, TC22-4 and antip53 was found in the normal mucosa or in gastritis area without GIM. The immunoreactivity of mAb Das-1 to GIM from Group C was higher (63\%) than Group IM $(39 \%)(p=0.069)$. In the GIM areas from Group DYS, mAb TC22-4 reactivity $(48 \%)$ was higher than that from Group IM (36\%). However, in the dysplastic areas of Group DYS, the mAb Das-1 reactivity was the highest (89\%). Each of the dysplastic areas and GIM mucosa away from this mucosal cancer area from the same patients reacted with mAb Das- 1 . Antip53 reactivity was absent in normal and inflamed mucosa as well as in GIM areas from Groups CG and IM (3\%), except in Group DYS where 4 of 27 (15\%) showed reactivity at the GIM areas. However, 59\% of dysplastic areas reacted with anti-p53.

\subsubsection{Changes of the GIM score after eradication of $\boldsymbol{H}$. pylori during prospective follow-ups}

GIM scores before and after treatment of $H$. pylori in each group are shown in Fig. 4. Although initially none of the patients in Group CG had GIM, during the follow-up period, 8 patients at 1 year and 6 additional patients developed GIM during subsequent 4 years ( $p=0.001$, Kruskal-Wallis test). Furthermore, GIM scores were higher in Group IM and DYS than in Group CG at 1 year after treatment ( $p<0.05$ and $p<0.0005$, respectively). At $2-4$ years after treatment, GIM scores continued to increase in Group CG and there was a significant difference in GIM score between Group CG and Group IM $(p<0.05)$ as well as Group DYS $(p<0.01)$ at 4 years. This difference suggests chronicity of the metaplastic process over a long 
time. Although in Group DYS there was some decline of GIM score over 4 years, it was not significant. The histologic scores in Group IM remained essentially unchanged (Fig. 4).

\subsubsection{Changes in the GIM phenotypes on the basis of mucin histochemistry before and after treatment for $H$. pylori}

Patients from Group CG did not have GIM before treatment, however, 14 patients (39\%) developed GIM during the 4 years of follow-up and GIM in these patients consisted of type I (complete type) in 8 (57\%) and type II or III (incomplete type) in $6(43 \%)$ patients (Table 2). In Group IM, type I and type II/III were found in $22(67 \%)$ and in $11(33 \%)$ patients respectively before treatment for eradication of $H$. pylori. On the contrary, in Group DYS, the majority (59\%) (16 out of 27) of GIM belonged to type II/III (incomplete type) compared to type I $(41 \%, 11$ of 27$)$, prior to treatment. The incidence of incomplete type of GIM was significantly $(p<0.05)$ higher in Group DYS than in Group IM. In Group IM, of the 22 patients initially classified as type I GIM, 7 (32\%) had "progressed" to type II/III, while in two no GIM was found after treatment and three of the 11 patients initially classified with type II/III had "regressed" to type I GIM. Similarly, in Group DYS, 5 of the 11 patients $(46 \%)$ with type I GIM changed to type II/III, and in one, no GIM was found following treatment. Three of 16 patients (19\%) initially classified as type II/III GIM regressed to type I and one had no GIM after eradication (Table 2).

\subsubsection{Reactivity to mAb Das-1, TC22-4 and anti-p53 in GIM during the follow-up period}

$\mathrm{mAb}$ Das-1 did not react with any of the 36 samples in Group CG who had chronic gastritis without GIM prior to treatment (Fig. 5). Of the 39\% of patients in Group CG who developed GIM during the 4 year follow-up period subsequent to the eradication of H. pylori, $43 \%$ (6 of 14) showed reactivity to $\mathrm{mAb}$ Das-1, similar to the incomplete (type II/III) determined by immunohistochemistry. Fig. 6A and 6B are an example from a patient in Group CG showing chronic gastritis in pretreatment biopsy (Fig. 6A) and subsequent development of GIM (Fig. $6 \mathrm{~B})$ despite eradication following triple therapy. However, no mAb Das-1 reactivity to GIM was found in this patient (Fig. 6C). The H\&E staining, and mAb Das-1 reactivities of serial sections of the biopsy specimen from a patient in Group IM are shown in Fig. 6D and E, respectively. Fig. $6 \mathrm{G}$ and $\mathrm{H}$ show serial sections from the biopsy specimen from a patient in Group DYS (GIM area) stained by H\&E and mAb Das-1 respectively. The mAb Das-1 reactivity is restricted to the glandular epithelium in the GIM areas (Fig. 6E and 6H). Both the non-goblet metaplastic cells and goblet cells reacted with mAb Das-1, and normal gastric mucosa did not react. Fig. $6 \mathrm{~J}$ and $6 \mathrm{~K}$ show serial sections from a patient in Group DYS with cancer stained by $\mathrm{H} \& \mathrm{E}$ and $\mathrm{mAb}$ Das-1 respectively. Cancer cells invading microscopically into the sub-mucosa can be seen. The reactivity with mAb Das-1 against the dysplastic glands is more diffuse and intense (Fig. 6K).

There were 30 patients (13 in Group IM and 17 in Group DYS) that reacted to mAb Das-1 before treatment. When the immunoreactivity in the biopsy tissue from the same patients were compared before and after treatment, in $40 \%$ of the patients the reactivity disappeared ( $\mathrm{p}<0.0001$ ) after eradication of $H$. pylori (Table 3, Fig. 6I), despite the presence of GIM. The disappearance of the reactivity was seen in both Group IM and Group DYS.

The reactivity of mAb TC22-4 is restricted to GIM areas both in goblet and non-goblet cells. The reactivity is dense globular dot like staining mainly along the apical areas (Fig. 6F). In Group DYS, the GIM areas and cancer areas also showed similar staining with TC22-4, as in 


\begin{tabular}{|c|c|c|c|c|c|}
\hline & \multicolumn{2}{|c|}{ Pretreatment } & \multicolumn{2}{|c|}{ Posteradiucation } \\
\hline & & Types & Number & Types & Number \\
\hline \multirow[t]{2}{*}{ Group CG } & $(n=36)$ & No GIM & & I & 8 \\
\hline & & & & II/III & 6 \\
\hline Total & & & & & 14 \\
\hline \multirow[t]{2}{*}{ Group IM } & $(n=33)$ & I & 22 & I & 13 \\
\hline & & 1 & 22 & II/III & 7 \\
\hline \multirow[t]{3}{*}{ Total } & & & & & 20 a \\
\hline & & U//U c & 11 & I & 3 \\
\hline & & & & II/III & 8 \\
\hline Total & & & & & 11 \\
\hline \multirow{2}{*}{$\begin{array}{l}\text { Group } \\
\text { DYS }\end{array}$} & $(\mathrm{n}=27)$ & I & 11 & I & 5 \\
\hline & & & & II/III & 5 \\
\hline \multirow[t]{3}{*}{ Total } & & & & & $10 \mathrm{~b}$ \\
\hline & & II/III & 16 & I & 3 \\
\hline & & & 10 & II/III & 12 \\
\hline Total & & & & & $15^{b}$ \\
\hline
\end{tabular}

${ }^{a}$ GIM disappeared in 2 patients after eradication.

$\mathrm{b}$ GIM disappeared in 2 patients after eradication.

c $P<0.05$ in the incidence of type II/III GIM between Group IM and Group DYS in pretreatment.

Table 2. Types of GIM on the basis of mucin histochemistry

\begin{tabular}{lcccc}
\hline & Pretreatment & \multicolumn{2}{c}{ Posteradiucation } & \\
\cline { 3 - 4 } & Positive & Positive & Negative & $P$ \\
\hline Groups IM + DYS & $30(100 \%)$ & $17(57 \%)$ & $12(40 \%)$ & $<0.0001$ \\
\hline Group IM & $13(100 \%)$ & $7(54 \%)$ & $5(38 \%)$ & $<0.01$ \\
Group DYS & $17(100 \%)$ & $10(59 \%)$ & $7(41 \%)$ & $<0.007$ \\
\hline
\end{tabular}

Table 3. Changes in the immunoreactivity of mAb Das-1-positive GIM after H. pylori eradication in the same patients

Figure 6F. Twelve of 33 patients (36\%) in Group IM were positive prior to treatment, and following treatment the reactivity declined to 6 of 29 (21\%) (Fig. 6M). There was no difference in TC22 reactivity before and after treatment. Seven patients in Group IM and 10 patients in Group DYS were positive for both mAb Das-1 and TC22-4 reactivity. Following eradication of $H$. pylori, the immunoreactivity for both the markers disappeared in 5 of the 7 patients in Group IM ( $\mathrm{p}<0.05)$. However, in only 3 of 10 patients in Group DYS was the reactivity absent. This was not significant (Table 4 ).

\begin{tabular}{lcccc}
\hline & Pretreatment & \multicolumn{2}{c}{ Posteradiucation } & \\
\cline { 3 - 4 } & Positive & Positive & Negative & $P$ \\
\hline Groups IM + DYS & $17(100 \%)$ & $9(53 \%)$ & $8(40 \%)$ & $<0.005$ \\
\hline Group IM & $7(100 \%)$ & $2(29 \%)$ & $5(38 \%)$ & $<0.05$ \\
Group DYS & $10(100 \%)$ & $7(70 \%)$ & $3(41 \%)$ & NS \\
\hline
\end{tabular}

Table 4. Changes in the immunoreactivity of TC22-4-positive GIM after H. pylori eradication in the same patients 

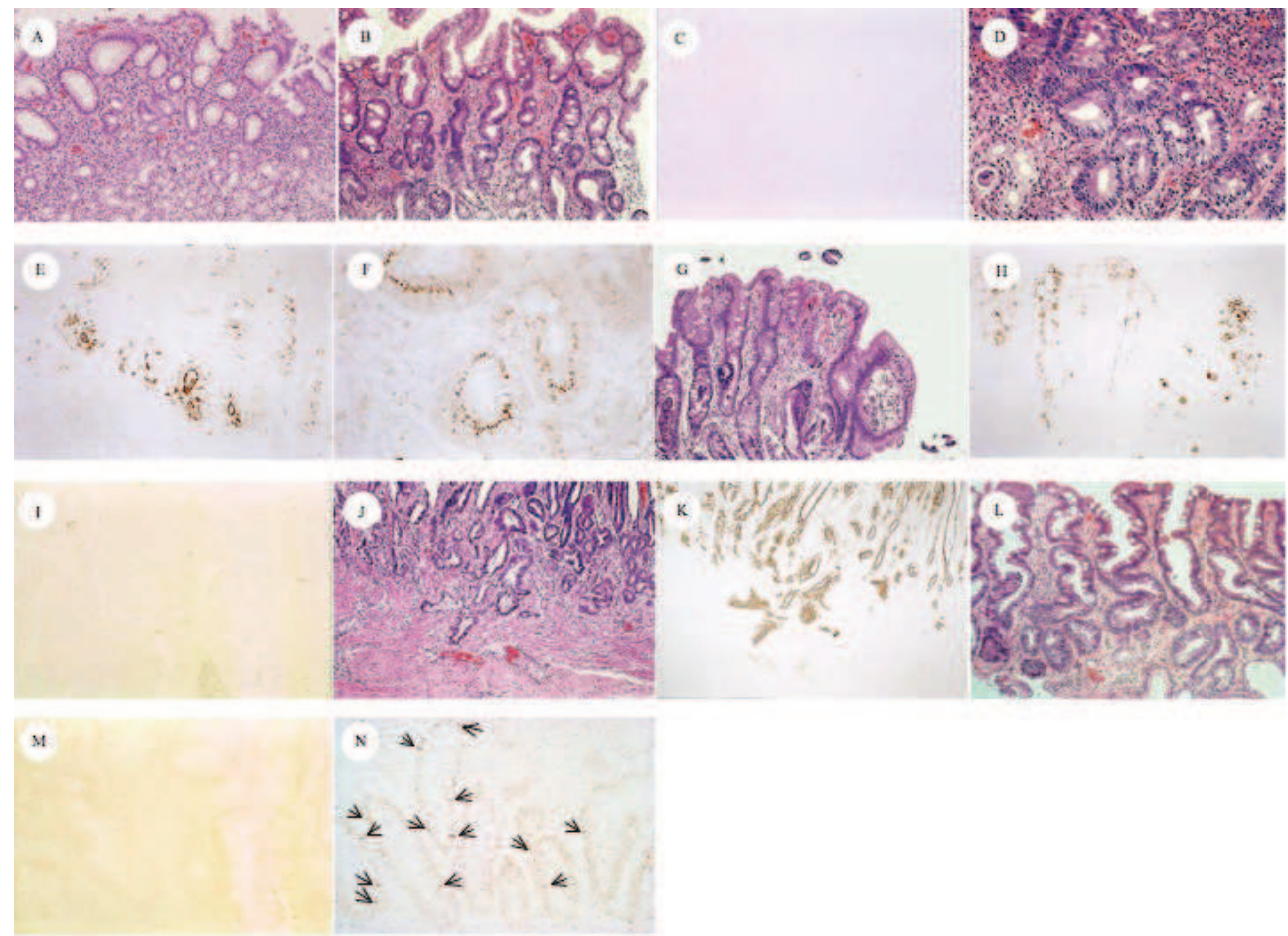

Fig. 6. Representative sections of H\&E and immunoperoxidase staining with $\mathrm{mAb}$ Das-1, TC22-4, and anti-p53. (A and B) Example of a patient from group CG whose gastric mucosa only had mild gastritis, (A) without any GIM before treatment (magnification, 200X), but (B) GIM clearly developed after eradication (magnification, 200X). (C) However, GIM did not react with $\mathrm{mAb}$ Das-1 after treatment (magnification, 200X). In a patient from group IM, serial sections from the initial biopsy specimen before eradication show (D) GIM (H\&E magnification, 200X) that reacted with both (E) mAb Das-1 (magnification, 200X) and (F) TC22-4 (magnification, 400X). Serial sections of the biopsy tissue from a patient from group DYS before treatment show $(\mathrm{G})$ GIM (H\&E magnification, 200X) and (H) reactivity to mAb Das-1 (magnification, 200X). A serial section of the same tissue also reacted with TC22-4 (figure not shown). (I) The reactivity to mAb Das-1 (magnification, 200X) disappeared in two fifths of the patients from both groups IM and DYS (Table 3) after H. pylori treatment $(\mathrm{p}<0.0001)$. ( $\mathrm{J}$ and $\mathrm{K})$ Representative pictures of the serial tissue sections from a patient in the severe dysplasia group (group DYS) stained with (J) H\&E and (K) mAb Das-1. (J) Cancerous glands, with microinvasion into the submucosa, seen in H\&E staining (magnification, 100X), and all of these tissue strongly reacted with (K) mAb Das-1 (magnification, 100X). (L) GIM in a patient from group IM after eradication of H. pylori. (M) TC22 reactivity disappeared in this patient (H\&E magnification, 200X). (N) GIM from a patient from group DYS stained with anti-p53. p53 protein staining is shown in scattered cells (arrows), mainly in the nuclei of the glands. 
The p53-positive nuclear staining was mainly detected in the dispersed cells mostly at the GIM glands located at the deeper plane (Fig. 6N, arrows). In Group IM, p53 expression was observed in only one of 33 patients before treatment, and its expression was noted in one additional patient during the follow-up period after treatment. In Group DYS, in the GIM areas, 4 of $27(15 \%)$ had p53 expression at initial examination. During the follow-up period, additional patients, 7 of 25 (28\%), exhibited p53 expression. However, in the dysplastic areas in Group DYS, p53 expression was high (16 of 27, 59\%). The p53 expression did not change in these patients during the follow-up period. All of the patients in Group DYS who were anti-p53 positive, also had mAb Das-1 reactivity and TC22 expression (both GIM and dysplastic areas).

\subsection{Study 2}

\subsubsection{K-ras codon 12 mutations in GIM}

The mutant K-ras in codon 12 was detected in 18 (46.2\%) of 39 GIM in Group IM and 1 (1.9\%) of 53 GIM areas away from cancer in Group DYS before eradication, and 2 (3.8\%) of 53 cancers, respectively. One case who had a K-ras mutation in Group DYS belonged to Group DYS-1. One of the 2 cancers which were positive for K-ras mutations was also positive in parallel with the GIM areas. Group IM showed a significantly more frequent incidence of K-ras codon 12 point mutations than Group DYS $(\mathrm{p}<0.005)$. Moreover, the incidence (46.2\%) of the K-ras gene alterations significantly decreased to $12.8 \%$ (5 of 39) after treatment in Group IM but not in Group DYS. Of the lesions with K-ras mutations in Group IM before treatment, GGT (Gly) showed AGT (Ser) transition in 9 (50.0\%), GAT (Asp) transition in $6(33.3 \%)$ and TGT (Cys) transversion in $3(16.7 \%)$. Following treatment, four (75.0\%) showed a transition to AGT (Ser) and 1 (25.0\%) showed a transition to GAT (Asp). Hence, mutation patterns showed convergence to Ser transformation by $H$. pylori treatment. The mutation pattern in the patient from Group DYS-1 was AGT (Ser). After eradication, the patterns of AGT (Ser) disappeared and one subject who had previously been negative for Kras mutation showed a positive finding for the K-ras mutation of GAT (Asp). The cancer showed two patterns: GCT (Ala) in 1 and GTT (Val) in 1 (Table 5).

\begin{tabular}{lcccc}
\hline & \multicolumn{4}{c}{ Helicobacter pylori eradication } \\
\cline { 2 - 5 } & Before & $\mathrm{n}$ & After & $\mathrm{n}$ \\
\hline Group IM & AGT (Ser) & 9 & AGT (Ser) & 4 \\
& GAT (Asp) & 6 & GAT (Asp) & 1 \\
Group DYS-1 & TGT (Cys) & 3 & & \\
Cancer areas & AGT (Ser) & 1 & GAT (Asp) & 1 \\
& GCT (Ala) & 1 & & \\
\hline
\end{tabular}

Table 5. Patterns of K-ras mutation in gastric intestinal metaplasia

\subsubsection{Cell kinetics of GIM}

PI and AI in IM before H. pylori eradication were $36.71 \%$ and $0.27 \%$ in Group IM, $45.69 \%$ and $0.52 \%$ in Group DYS, respectively. PI in Group DYS was significantly higher than that in Group IM ( $\mathrm{p}<0.05)$. AI also showed a similar tendency, but the difference did not reach statistical significance. Regarding the cell kinetics after treatment in each group, PI and AI 
were $40.43 \%$ and $0.47 \%$ in Group IM, $42.32 \%$ and $0.83 \%$ in Group DYS, respectively. Although there were no significant changes in the PI before and after H. pylori eradication, the level of AI increased after H. pylori eradication in both groups $(\mathrm{p}<0.05$ in Group IM) (Table 6).

\begin{tabular}{|c|c|c|c|c|c|c|}
\hline & \multicolumn{2}{|c|}{ PI } & \multicolumn{2}{|c|}{ AI } & \multicolumn{2}{|c|}{$\mathrm{AI} / \mathrm{PI}$ ratio } \\
\hline & \multicolumn{2}{|c|}{ H. pylori eradication } & \multicolumn{2}{|c|}{ H. pylori eradication } & \multicolumn{2}{|c|}{ H. pylori eradication } \\
\hline & Before & After & Before & After & Before & After \\
\hline Group IM & $36.71 \pm 2.71^{*}$ & $40.43 \pm 2.71$ & $0.27 \pm 0.07$ & $0.47 \pm 0.10$ & $\begin{array}{c}0.020 \pm \\
0.012\end{array}$ & $\begin{array}{c}0.013 \pm \\
0.004\end{array}$ \\
\hline Group DYS & $45.69 \pm 2.65^{*}$ & $42.32 \pm 3.20$ & $0.52 \pm 0.16$ & $0.83 \pm 0.30$ & $\begin{array}{c}0.010 \pm \\
0.003\end{array}$ & $\begin{array}{c}0.021 \pm \\
0.001\end{array}$ \\
\hline
\end{tabular}

${ }^{*} \mathrm{p}<0.05$, Numbers are mean \pm standard error. PI, proliferative indices; AI, apoptotic indices; H. pylori, Helicobacter pylori

Table 6. Comparison of cell kinetics before and after Helicobacter pylori eradication

\begin{tabular}{|c|c|c|c|c|c|c|}
\hline & \multicolumn{2}{|c|}{ Neutrophils } & \multicolumn{2}{|c|}{ Mononucler cells } & \multicolumn{2}{|c|}{ Intestinal metaplasia } \\
\hline & \multicolumn{2}{|c|}{ H pylori eradication } & \multicolumn{2}{|c|}{ H pylori eradication } & \multicolumn{2}{|c|}{ H pylori eradication } \\
\hline & Before & After & Before & After & Before & After \\
\hline Group IM & $0.65 \pm 0.10 \mathrm{a}$ & $0.03 \pm 0.03 \mathrm{a}$ & $1.54 \pm 0.11 \mathrm{c}, \mathrm{d}$ & $1.03 \pm 0.10^{c}$ & $1.4 \pm 0.6^{\mathrm{f}}$ & $1.3 \pm 0.8$ \\
\hline Group DYS & $0.40 \pm 0.13$ & $0.20 \pm 0.09$ & $1.15 \pm 0.17 \mathrm{~d}$ & $1.00 \pm 0.10$ & $2.1 \pm 0.9 \mathrm{f}$ & $1.9 \pm 0.9$ \\
\hline
\end{tabular}

$\mathrm{a}, \mathrm{c}, \mathrm{d} \mathrm{p}<0.0001, \mathrm{c} \mathrm{p}<0.005, \mathrm{~d} \mathrm{p}<0.05, \mathrm{e} \mathrm{p}<0.005, \mathrm{f} \mathrm{p}<0.05$, Numbers are mean \pm standard error. H. pylori, Helicobacter pylori

Table 7. Comparison of scores for histological findings before and after Helicobacter pylori eradication

\subsubsection{Inflammation and GIM scores}

The grade of inflammation and GIM before and after treatment was shown in Table 7. All GIMs investigated in the current study were diagnosed as incomplete type without dysplastic glands. At 1 year after successful H. pylori eradication, the median score of inflammation such as neutrophils and mononuclear cells significantly improved in Group A $(p<0.0001$ and $p<0.005$, respectively), but it did not change in Group B. The score of mononuclear cells was significantly higher in Group IM than in Group DYS $(p<0.05)$, although no significant difference was observed in the neutrophils between the two groups. The GIM scores were also significantly higher in Group DYS than in Group IM before $H$. pylori therapy $(\mathrm{p}<0.05)$. After $1 \mathrm{yr}$ of follow-up, however, the GIM score remained unchanged in comparison to their pretreatment values in both Groups IM and DYS.

\section{Discussion}

\subsection{Study 1}

In this study, we show that $H$. pylori eradication did not significantly improve GIM histologically, but changed the cellular phenotype, as evidenced by the significant reduction 
of reactivity against monoclonal antibody, $\mathrm{mAb}$ Das-1, indicating a reduction of colonic phenotype (incomplete type) of metaplasia over the course of subsequent follow-up, up to 4 years. This was further supported by prospectively following the same patients who were initially positive. We further demonstrate that eradication of $H$. pylori might reverse TC22 expression at the earlier stage (Group IM). However, once dysplasia/cancer has developed in the background mucosa (Group DYS), both cellular phenotype, as detected by mAb Das-1 and neoplastic marker TC22, did not show significant change following $H$. pylori eradication. These data support the conclusion reported by some investigators that at a certain stage of progression of GIM there is a "Point of no return" (Wong et al., 2004; Wright, 1998).

GIM is considered to be a pre-cancerous lesion of the stomach (Uemura et al., 2001; Correa \& Shiao, 1994; Wong et al., 2004), especially when it is incomplete or colonic type (type II \& type III) metaplasia (Filipe \& Jass, 1986; Mirza et al., 2003). There are an equal number of studies showing either improvement or no change in the incidence of gastric cancer following eradication of $H$. pylori (Table 1). However, a large population based study showed decrease in cancer incidence following eradication of H. pylori (You et al., 2006; Take et al., 2005; Wong et al., 2004). The reasons for these discrepancies are the limited number of patients in some of the series, short follow-up, and also unawareness of the stage when the treatment was initiated. Our results support the reports that showed that 2 years following H. pylori eradication there was no significant histologic improvement in GIM (Forbes et al. 1996; Tucci et al., 1998; Tepes et al., 1999; Kim et al., 2000; Kuipers et al., 2004), although two other reports showed improvement (Kokkola et al., 2002; Correa et al., 2000). It was suggested that effective anti-H. pylori treatment might interfere with the pre-cancerous process, mostly by increasing the rate of regression of GIM (Correa et al., 2000). Our study demonstrates that this "regression" may be related to the change of cellular phenotype. Taking into account previous studies and our finding, it, therefore, appears that eradication of the bacteria may not influence the course of the histologic process (Farinati et al., 1998). We further demonstrate that even after eradication of $H$. pylori, in 14 of 36 patients (39\%) who at initial diagnosis had gastritis without GIM (Group CG), developed GIM subsequently during the 4 years of follow-up evaluation. However, it appears that these GIMs are mostly of complete type (type I) of metaplasia that have a low risk for gastric carcinoma (Filipe et al. 1986; Mirza et al., 2003; Wong et al., 2004). Wong et al suggested that eradication of $H$. pylori should be done prior to the development of GIM in order to prevent gastric cancer (Wong et al., 2004). Our data further support that once the dysplastic process has occurred, eradication of $H$. pylori may not be helpful in changing the course (Sakaki et al., 2002; Asaka et al., 2002). Some investigators showed that older subjects are more likely to demonstrate progression in GIM in persistent $H$. pylori infection than younger patients (Sung et al., 2000; Sakaki et al., 2002; Asaka et al., 2002). Indeed, the average age of the patients in Group DYS was significantly higher than from Group CG and IM ( $<<0.005$ and $\mathrm{p}<0.05$, respectively), indicating that GIM in Group DYS was in an advanced stage among the three groups. The mean age of the patients in Group IM was in between the mean ages of Group CG and Group DYS. Furthermore, the GIM score in Group DYS is significantly higher than Group IM $(\mathrm{p}<0.05)$. Hence, our findings support the postulation that GIM grade ensues sequentially over a period of a decade (Uemura et al., 2001; Correa et al., 1990).

We previously reported a highly significant $(\mathrm{p}<0.0001)$ reactivity of mAb Das- 1 against GIM adjacent to gastric cancer when compared to GIM from non-cancer patients (Mirza et al., 2003). We further reported that the reactivity of mAb Das-1 in other precancerous 
conditions, such as Barrett's epithelium was highly sensitive and specific (100\%) (Das et al., 1994). In the small intestine, although mAb Das-1 does not react with normal epithelium, $\mathrm{mAb}$ Das-1 reactivity was evident in most of the small intestinal adenoma and adenocarcinoma (Onuma et al., 2001). All of these studies suggest a colonic or incomplete phenotype of metaplasia in the pre-cancerous conditions of the esophagus, stomach and small intestine. The present study shows that the immunoreactivity to mAb Das-1 was higher in the GIM in patients from Group DYS compared to those from Group IM $(\mathrm{p}<0.05)$ at the initial diagnosis before $H$. pylori eradication. Furthermore, mAb Das-1 reacted with GIM areas away from the dysplastic areas from each of the patients whose dysplastic areas were positive with mAb Das-1. Twelve out of 30 patients (40\%) with GIM from Groups IM and DYS who were positive to mAb Das- 1 before treatment, lost the reactivity $(\mathrm{p}<0.0001)$ after eradication of $H$. pylori, suggesting the reversibility of the process if $H$. pylori is eradicated. Thus, the patients with $H$. pylori infection with GIM that showed the reactivity for mAb Das-1 (incomplete type of metaplasia) may benefit from eradication for future development of cancer. This observation may be clinically useful for surveillance.

TC22 is a neoplastic marker. It is expressed by transformed cells but not by normal epithelial cells (Lin et al., 2002). In the present study, TC22-4 reactivity in GIM did not significantly change after eradication in both Group IM and DYS. Thus, the reactivity of Das- 1 against GIM may suggest an early stage of neoplastic process compared with that of TC22-4. In a pilot study, we also observed that the frequency of mAb TC22-4 reactivity in gastric cancer was 86\% (19/22) (Das-Bhattacharya et al., 2001). In each of these 19 patients, the GIM area away from the cancer area was also positive for TC22. Therefore, eradication of H. pylori at this stage may not be beneficial to avoid cancer development.

Mutation of the tumor suppressor gene p53 has been described in gastric carcinogenesis. Some GIM shows p53 mutations and its overexpression (El-Zimaity et al., 2001; Shiao et al., 1994; Imatani et al., 1996 ; Hamamoto et al., 1997; Jones et al., 1997), and accumulation of p53 is detected in gastric mucosa infected with H. pylori (Hibi et al., 1997; Satoh et al., 2001). Of interest, it was reported that p53 overexpression decreased after eradication of $H$. pylori (Hibi et al., 1997; Jones et al., 1997). Some of the discrepancies may be due to various reagents, and in some reports, p53 positivity index was used by calculating p53-positive cells in gastric glands (Hibi et al., 1997; Jones et al., 1997). p53 expression in our patients with GIM was very low, 3\% in Group IM, and only 15\% in Group DYS, and there was no regression following treatment. In the patients from Group DYS before treatment, the incidence $(15 \%)$ of p53 expression was significantly lower than that of mAb TC22-4 reactivity in GIM areas (48\%). In the paired samples of tissue with dysplasia/cancer, the overexpression of p53 increased from 15\% in the GIM areas to 59\% in the dysplastic areas. However, TC22 expression was essentially the same. Thus, p53 protein accumulation seems to be a late event, whereas TC22-4 expression is an earlier event, as also reported in colonic neoplasm (Lin et al., 2002).

As many investigators pointed out, it will certainly need a much longer follow-up period, more than 4 yrs., in order to evaluate the effect of eradication for the cancer prevention. However, the end-point of the current study was to assess the changes in the expression of biomarkers in GIM, one associated with cell phenotype and the other associated with epithelial neoplasia, but not the development of gastric cancer after $H$. pylori treatment. Indeed, we recently found that cell kinetics and genetic alterations, i.e. microsatellite instability and K-ras mutations in GIM, play a role in the early events leading to gastric carcinogenesis, and H. pylori eradication settled these genetic events during only the one- 
year post-treatment period (Tanaka et al. 2006; Watari et al. 2008). Thus, we believe that the follow-up period, up to 4 yrs in this study, is enough to investigate the changes in cellular phenotype and neoplastic biomarkers related to carcinogenesis after H. pylori eradication. Taking our present and previous data (Tanaka et al. 2006; Watari et al. 2008) together, eradication of $H$. pylori may inhibit this intracellular dysfunction; thereby may inhibit carcinogenesis.

The data presented in the current study based on careful initial stratification of patients by an independent expert pathologist without the knowledge of clinical information, and prospective follow-up for 4 years, provide important information about the cellular changes in the GIM using the two novel biomarkers. Strategies to identify individuals who are at a "high risk" for gastric cancer screening are very much needed. Immunostaining with mAb Das-1 and TC22-4, that can easily be performed along with routine histology, may be clinically useful in this regard.

\subsection{Study 2}

The mutant K-ras was detected in only $3.8 \%$ of the cancer, and this finding was consistent with the findings of previous reports (Tahara et al. 1993; Arber et al., 2000; Hiyama et al., 2002). On the other hand, we found a significantly higher frequency of K-ras mutations in GIM (46.2\%) in patients with chronic gastritis in comparison those with gastric cancer $(1.9 \%)$ with $H$. pylori infection. Furthermore, we also observed that K-ras mutations significantly decreased to $12.8 \%$ after $H$. pylori eradication. Regarding the K-ras mutation types in Group IM, various patterns such as G to A (Ser and Asp) transitions and G to T (Cys) transversion were seen before treatment. It is interesting to note that after $H$. pylori eradication, most individuals $(80.0 \%, 4$ of 5) showed transition to AGT (Ser) while other mutation patterns such as TGT (Cys) and GAT (Asp) disappeared. In our data, since the number of cases that could be investigated based on the changes in the K-ras mutation patterns was small, statistical significance could therefore not be applied to them. These results indicate, however, that K-ras mutations in GIM with GAT and TGT types may thus be early and unstable in gastric carcinogenesis because they disappeared after $H$. pylori treatment. AGT (Ser) still remained in most cases treated with $H$. pylori in our study. Gong et al. reported the $\mathrm{G}$ to A transition (Ser) to be important for the progression of gastric mucosal cells to a more advanced premalignant stage (Gong et al., 1999). Lee et al. also showed a similar result, so that frequent $G$ to A transversions were detected in gastric cancers (Lee et al., 1995). Taking both our results and other data into consideration, mutations with AGT (Ser) were thus considered to more likely be advantageous in K-ras gene alterations. Hiyama et al. reported interesting data in which $\mathrm{K}$-ras mutations were detected in $3.0 \%$ in the background mucosa without cancer and in $10.9 \%$ in those with cancer, thus indicating a significant difference. In addition, most $(70 \%)$ of the patterns of K-ras mutations detected in chronic gastritis patients were $\mathrm{G}$ to $\mathrm{C}$ transitions (GCT, Ala) (Hiyama et al., 2002). However, their data do not show $\mathrm{K}$-ras gene alterations in only GIM, and thus their findings are different from those of our investigation. In the current study, we used a laser capture microdissection system to extract DNA from GIM. This method allows the procurement of relatively pure metaplastic cell populations from the complex heterogeneous cell mixtures (Bonner et al., 1997). Therefore, it is considered that the specificity of genetic alterations in DNA extracted selectively from GIM (Dillon et al., 2001). Our results may suggest that the mutations with AGT (Ser) is important in gastric tumorigenesis, but not in others. We investigated here on K-ras 
oncogene alterations in GIM using only one biopsy sample obtained from the antrum. It will be necessary to study whether the patients with mutations have the same mutation in multiple GIM foci in each patient in order to confirm more clearly the role of K-ras mutation in GIM.

H. pylori eradication dramatically improved the inflammation scores, i.e. neutrophils and mononuclear cells, but not the degree of GIM, thus confirming the findings of previous studies in which the effect of $H$. pylori eradication therapy led to an improvement in the severity of inflammation (Witteman et al., 1995; van der Hulst et al., 1997). However, no significant improvement in the inflammation scores was found in patients with gastric cancer (Group DYS). Although the reason cannot be clearly explained, one possibility for this finding may be the small number patients investigated in comparison to those of Group IM. Interestingly, the score of mononuclear cells in Group IM showed a significantly higher level than that in Group DYS at the pretreatment assessment although no significant differences in the neutrophil scores were observed between Groups IM and DYS. Recently, Brembeck et al have reported a fascinating data that they generated a novel mouse model in which the cytokeratin 19 promotor, specifically active in pancreatic ductal cells, is fused to mutant K-ras (Brembeck et al., 2003). These results showed dramatic evidence of lymphocytic infiltration around the periductal area, in both the interlobular and intralobular pancreas of transgenic mice, which may thus act as an adaptive immune response to activated ras-mediated signaling. Taking both our findings and previous results into consideration, a frequent K-ras mutation in GIM may therefore be associated with evidence of lymphocyte infiltration but not with gastric carcinogenesis, even though the K-ras gene is considered to be an oncogene.

In the present study, we first found the cellular proliferation of GIM to significantly be upregulated in patients with gastric cancer more than in those without gastric cancer. As for apoptosis, there was a similar tendency even though no significant difference was seen. This finding supports the report of Shiotani et al that GIM results in proliferation-dominant cell kinetics may be one of the components of gastric carcinogenesis (Shiotani et al., 2005). Commonly, an imbalance of cell proliferation and apoptosis is known to play a role in cancer development, and tumor progression should be thus be considered in the context of both proliferative activity and cell loss (Wyllie, 1996). One of the pathways by which $H$. pylori is linked to gastric carcinogenesis may be related to the disruption of the cell kinetics. Uemura et al. reported that $H$. pylori eradication inhibited the development of new cancers in patients who underwent EMR for 2 years after EMR, while $9 \%$ of the patients who were not treated with this treatment developed new early stage gastric cancers after 3 years of follow-up (Uemura et al., 1997). From the standpoint of this clinical report by Uemura et al and our results, the increase of apoptosis in GIM by the clearance of $H$. pylori may be associated with the prevention of cancer development. To our knowledge, there has only been one study that has assessed the cell kinetics in $H$. pylori-associated GIM in patients with gastritis both before and after $H$. pylori eradication, although the sample size investigated in that study was small (14 cases) (Leung et al., 2001). They demonstrated a remarkable reduction in proliferation whereas the degree of apoptosis remained unaltered in GIM by treatment, by which the clearance of $H$. pylori may retard gastric carcinogenesis. However, we failed to detect such an association in the current study. This discrepancy seems to be derived from a few factors: namely, the difference in the sample number and the sampling error. As mentioned in the results, the severity of GIM was significantly higher in patients with cancer (Group DYS-1) than in those with chronic gastritis (Group IM) prior to 
treatment. Hence, an evaluation of the cell kinetics in GIM from the Group IM cases was therefore particularly difficult.

We recently found microsatellite instability (MSI) as a genetic alteration in H. pylori-related GIM to play a role in the early events leading to gastric carcinogenesis. H. pylori eradication reduced MSI during the one-year post-treatment period (Tanaka et al., 2006). In this prospective study, however, our current results suggest that K-ras codon 12 mutations in GIM may not be associated with gastric carcinogenesis. There are early events in K-ras mutations, which are influenced by inflammation-related $H$. pylori infection, and some mutations such as AGT (Ser) may thus be selected by eradication. Furthermore, these unstable K-ras mutations in GIM may be related to the lymphocyte infiltration caused by $H$. pylori infection. If $H$. pylori is eradicated before the development of stable mutations, then the risk of gastric cancer will likely be prevented. Furthermore, apoptosis in GIM showed the increase based on the treatment. Our 1-year prospective study may explain that the prevention of gastric cancer by H. pylori therapy is not associated with an improvement of K-ras mutations and the degree of GIM, but up-regulation in apoptosis control in GIM contributes to retard gastric carcinogenesis.

\section{Conclusions}

H. pylori eradication does not reduce the histologic GIM score, but changes the cellular phenotype of GIM. This change of phenotype may be an important factor in the reduction of cancer incidence after eradication of H. pylori. Furthermore, K-ras mutations in GIM do not always play a role in gastric carcinogenesis but cell kinetics, especially apoptosis, in GIM may contribute it.

\section{Acknowledgements}

This work was supported in part by a research grant (National Institute of Diabetes and Digestive and Kidney Disease, RO1DK63618 to K.M.D.) from the National Institutes of Health (Bethesda, MD). The authors would like to thank Ms. Harumi Suzuki for valuable help in preparing the slide sections.

\section{References}

Arber, N.; Shapira, I. \& Ratan, J., et al. (2000). Activation of c-K-ras mutations in human gastrointestinal tumors. Gastroenterology, Vol. 118, No. 6, pp. 1045-1050

Asaka, M.; Sugiyama, T. \& Nobuta, A., et al. (2001). Atrophic gastritis and intestinal metaplasia in Japan: results of a large multicenter study. Helicobacter, Vol. 6, No. 4, pp. 294-299.

Biancone, L.; Mandal, A. \& Yang, H., et al. (1995). Production of immunoglobulin G and G1 antibodies to cytoskeletal protein by lamina propria cells in ulcerative colitis. Gastroenterology, Vol. 109, No. 1, pp. 3-12

Bonner, RF.; Emmert-Buck, M. \& Cole, K., et al. (1997). Laser capture microdissection: molecular analysis of tissue. Science, Vol. 278, No. 5342, pp. 1481-1483.

Brembeck, FH.; Schreiber, FS. \& Deramaudt, TB., et al. (2003). The mutant K-ras oncogene causes pancreatic periductal lymphocytic infiltration and gastric mucous neck cell hyperplasia in transgenic mice. Cancer Res, Vol. 63, No. 9, pp. 2005-2009 
Chaubert, P.; Benhattar, J. \& Saraga, E., et al. (1994). K-ras mutations and p53 alterations in neoplastic and nonneoplastic lesions associated with longstanding ulcerative colitis. Am J Pathol, Vol. 144, No. 4, pp. 767-775

Cooper, GM. (1995). Guanine nucleotide binding proteins. In: Oncogenes. Ed. 2, Sudbury, MA: Jones and Bartlett Publishers, pp. 222-242

Correa, P. (1988). A human model of gastric carcinogenesis. Cancer Res, Vol. 48, No. 13, pp. 3554-3560

Correa, P.; Fox, J. \& Fontham, E., et al. (1990). Helicobacter pylori and gastric carcinoma. Serum antibody prevalence in populations with contrasting cancer risks. Cancer, Vol. 66, No. 12, pp. 2569-2574

Correa, P.; Haenszel, W. \& Cuello, C., et al. (1990). Gastric precancerous process in a high risk population: cohort follow-up. Cancer Res, Vol. 50, No. 15, pp. 4737-4740

Correa, P. \& Shiao, YH. (1994). Phenotypic and genotypic events in gastric carcinogenesis. Cancer Res, Vol. 54 (7 suppl), pp. 1941s-1943s

Correa, P. (1995). Helicobacter pylori and gastric carcinogenesis. Am J Surg Pathol, Vol. 19 (Suppl 1), pp. S37-S43

Correa, P.; Fontham, ET. \& Bravo, JC., et al. (2000). Chemoprevention of gastric dysplasia: randomized trial of antioxidant supplements and anti-Helicobacter pylori therapy. J Natl Cancer Inst, Vol. 92, No. 23, pp. 1881-1888

Das-Bhattacharya, S.; Walton, K. \& Watari, J., et al. (2001). Expression of a novel human tropomyosin isoform, TC22, in gastric intestinal metaplasia associated with gastric carcinoma. Gastroenterology, Vol. 122, A129

Das, KM.; Sakamaki, S. \& Vecchi, M., et al. (1987). The production and characterization of monoclonal antibodies to a human colonic antigen associated with ulcerative colitis: cellular localization of the antigen by using the monoclonal antibody. $J$ Immunol, Vol. 139, No. 1, pp. 77-84

Das, KM.; Dasgupta, A. \& Mandal, A., et al. (1993). Autoimmunity to cytoskeletal protein tropomyosin: a clue to the pathogenetic mechanism for ulcerative colitis. J Immunol, Vol. 150, No. 3, pp. 2487-2493

Das, KM.; Prasad, I. \& Garla, S., et al. (1994). Detection of a shared colon epithelial epitope on Barrett epithelium by a novel monoclonal antibody. Ann Intern Med, Vol. 120, No. 9, pp. 753-756

Dillon D, Zheng K, Costa J. (2001). Rapid, efficient genotyping of clinical tumor samples by laser-capture microdissection/PCR/SSCP. Exp Mol Pathol, Vol. 70, No. 3, pp. 195200

Dixon, MF.; Genta, RM. \& Yardley, JH., et al. (1996). Classification and grading of gastritis. The updated Sydney System. International Workshop on the Histopathology of Gastritis, Houston 1994. Am J Surg Pathol, Vol. 20, No. 10, pp. 1161-1181

El-Omar, EM.; Oien, K. \& Murray, LS., et al. (2000). Increased prevalence of precancerous changes in relatives of gastric cancer patients: critical role of $\mathrm{H}$. pylori. Gastroenterology, Vol. 118, No. 1, pp. 22-30

El-Zimaity, HM.; Ramchatesingh, J. \& Saeed, MA., et al. (2001). Gastric intestinal metaplasia: subtypes and natural history. J Clin Pathol, Vol. 54, No. 9, pp. 679-683

Farinati, F.; Foschia, F. \& Di Mario, F., et al. (1998). H. pylori eradication and gastric precancerous lesions. Gastroenterology, Vol. 115, No. 2, pp. 512-514 
Filipe, MI. \& Jass, JR. (1986). Intestinal metaplasia subtypes and cancer risk. In: Filipe MI, Jass JR, eds. Gastric carcinoma. Edinburgh: Churchill Livingstone, pp. 212-236.

Filipe, MI.; Munoz, N. \& Matko, I., et al. (1994). Intestinal metaplasia types and the risk of gastric cancer: a cohort study in Slovenia. Int J Cancer, 1994;Vol. 57, No. 3, pp. 324329

Forbes, GM.; Warren, JR. \& Glaser, ME., et al. (1996). Long-term follow-up of gastric histology after Helicobacter pylori eradication. J Gastroenterol Hepatol, Vol. 11, No. 7, pp. 670-673

Gavrieli, Y.; Sherman, Y. \& Ben-Sasson, SA. (1992). Identification of programmed cell death in situ via specific labeling of nuclear DNA fragmentation. J Cell Biol, Vol. 119, No. 3, pp. 493-501

Geng, X.; Biancone, L. \& Dai, HH., et al. (1998). Tropomyosin isoforms in intestinal mucosa: production of autoantibodies to tropomyosin isoforms in ulcerative colitis. Gastroenterology, Vol. 114, No. 5, pp. 912-922

Genta, RM.; Lew, GM. \& Graham, DY. (1993). Changes in the gastric mucosa following eradication of Helicobacter pylori. Mod Pathol, Vol. 6, No. 3, pp. 281-289

Gong, C.; Mera, R. \& Bravo, JC., et al. (1999). KRAS mutations predict progression og preneoplastic gastric lesions. Cancer Epidemiol Biomark Prev, Vol. 8, No. 2, pp. 167171

Graham, DY. (2000). Helicobacter pylori infection is the primary cause of gastric cancer. $J$ Gastroenterol, Vol. 35 (suppl 12), pp. 90-97

Griffel, LH.; Amenta, PS. \& Das, KM. (2000). Use of a novel monoclonal antibody in diagnosis of Barrett's esophagus. Dig Dis Sci, Vol. 45, No. 1, pp. 40-48

Halstensen, TS.; Das, KM. \& Brandtzaeg, P. (1993). Epithelial deposits of immunoglobulin G1 and activated complement colocalise with the M(r) $40 \mathrm{kD}$ putative autoantigen in ulcerative colitis. Gut, Vol. 34, No. 5, pp. 650-657

Hamamoto, T.; Yokozaki, H. \& Semba, S., et al. (1997). Altered microsatellites in incompletetype intestinal metaplasia adjacent to primary gastric cancers. J Clin Pathol, Vol. 50, No. 10, pp. 841-846

Hibi, K.; Mitomi, H. \& Koizumi, W., et al. (1997). Enhanced cellular proliferation and p53 accumulation in gastric mucosa chronically infected with Helicobacter pylori. Am J Clin Pathol, Vol. 108, No. 1, pp. 26-34

Hiyama, T.; Haruma, K. \& Kitadai, Y., et al. (2002). K-ras mutation in Helicobacter pyloriassociated chronic gastritis in patients with and without gastric cancer. Int J Cancer, Vol. 97, No. 5, pp. 562-566

Hoshi, T.; Sasano, H. \& Kato, K., et al. (1999). Cell damage and proliferation in human gastric mucosa infected by Helicobacter pylori-A comparison before and after $\mathrm{H}$ pylori eradication in eradication in non-atrophic gastritis. Hum Pathol, Vol. 30, No. 12, pp. $1412-1417$

Imatani, A.; Sasano, H. \& Yabuki, N., et al. (1996). In situ analysis of tissue dynamics and p53 expression in human gastric mucosa. J Pathol, Vol. 179, No. 1, pp. 39-42

International Agency for Research on Cancer. (1994). IARC monographs on the evaluation of carcinogenic risks to humans. Schistosomes, liver flukes and Helicobacter pylori. Lyon: IARC, vol. 61, pp. 177-240 
Jones, NL.; Shannon, PT. \& Cutz, E., et al. (1997). Increase in proliferation and apoptosis of gastric epithelial cells early in the natural history of Helicobacter pylori infection. Am J Pathol, Vol. 151, No. 6, pp. 1695-1703

Kim, N.; Lim, SH. \& Lee, KH., et al. (2000). Long-term effects of Helicobacter pylori eradication on intestinal metaplasia in patients with duodenal and benign gastric ulcers. Dig Dis Sci, Vol. 45, No. 9, pp. 1754-1762

Kokkola, A.; Sipponen, P. \& Rautelin, H., et al. (2002). The effect of Helicobacter pylori eradication on the natural course of atrophic gastritis with dysplasia. Aliment Pharmacol Ther, Vol. 16, No. 3, pp. 515-520

Kuipers, EJ.; Nelis, GF. \& Klinkenberg-Knol, EC., et al. (2004). Cure of Helicobacter pylori infection in patients with reflux oesophagitis treated with long term omeprazole reverses gastritis without exacerbation of reflux disease: results of a randomised controlled trial. Gut, Vol. 53, No. 1, pp. 12-20

Lee, KH,: Lee, JS. \& Suh, C., et al. (1995). Clinicopathologic significance of the K-ras gene codon 12 point mutation in stomach cancer. An analysis of 140 cases. Cancer, Vol. 75, No. 12 , pp. $2794-2801$

Lees-Miller, JP. \& Helfman, DM. (1991). The molecular basis for tropomyosin isoform diversity. Bioessays, Vol. 13, No. 9, pp. 429-437

Leung, WK.; Yu, J. \& To, KF., et al. (2001). Apoptosis and proliferation in Helicobacter pylori-associated gastric intestinal metaplasia. Aliment Pharmacol Ther, Vol. 15, No. 9, pp. 1467-1472

Levi, S.; Urbano-Ispizua, A. \& Gill, R., et al. (1991). Multiple K-ras codon 12 mutations in cholangiocarcinomas demonstrated with a sensitive polymerase chain reaction technique. Cancer Res, Vol. 51, No. 13, pp. 3497-3502

Ley, C.; Mohar, A. \& Guarner, J., et al. (2004). Helicobacter pylori eradication and gastric preneoplastic conditions: a randomized, double-blind, placebo-controlled trial. Cancer Epidemiol Biomarkers Prev, Vol. 13, No. 1, pp. 4-10

Lin, JJ.; Warren, KS. \& Wamboldt, DD., et al. (1997). Tropomyosin isoforms in nonmuscle cells. Int Rev Cytol, Vol. 170, pp. 1-38

Lin, JL.; Geng, X. \& Bhattacharya, SD., et al. (2002). Isolation and sequencing of a novel tropomyosin isoform prefentially associated with colon cancer. Gastroenterology, Vol. 123, No. 1, pp. 152-162

Mera, R.; Fontham, ET. \& Bravo, LE., et al. (2005). Long term follow up of patients treated for Helicobacter pylori infection. Gut, Vol. 54, No. 11, pp.1536-1540

Miehlke, S.; Hackelsberger, A. \& Meining, A., et al. (1998). Severe expression of corpus gastritis is characteristic in gastric cancer patients infected with Helicobacter pylori. Br J Cancer, Vol. 78, No. 2, pp. 263-266

Mirza, ZK.; Das, KK. \& Slate, J., et al. (2003). Gastric intestinal metaplasia as detected by a novel biomarker is highly associated with gastric adenocarcinoma. Gut, Vol. 52, No.6, pp. 807-812

Moss, SF.; Calam, J. \& Agarwal, B., et al. (1996). Induction of gastric epithelial apoptosis by Helicobacter pylori. Gut, Vol. 38, No. 4, pp. 498-501

Nardone, G.; Staibano, S. \& Rocco, A., et al. (1999). Effect of Helicobacter pylori infection and its eradication on cell proliferation, DNA status, and oncogene expression in patients with chronic gastritis. Gut, Vol. 44, No. 6, pp. 789-799 
Novy, RE.; Lin, JL. \& Lin CS, et al. (1993). Human fibroblast tropomyosin isoforms: characterization of cDNA clones and analysis of tropomyosin isoform expression in human tissues and in normal and transformed cells. Cell Motil Cytoskeleton, Vol. 25, No. 3, pp. 267-281

Ohkusa, T.; Fujiki, K. \& Takashimizu, I., et al. (2001). Improvement in atrophic gastritis and intestinal metaplasia in patients in whom Helicobacter pylori was eradicated. Ann Int Med, Vol. 134 No. 5, pp. 380-386

Onuma, EK.; Amenta, PS. \& Ramaswamy, K., et al. (2000). Autoimmunity in ulcerative colitis (UC): a predominant colonic mucosal B cell response against human tropomyosin isoform 5. Clin Exp Immunol, Vol. 121, No. 3, pp. 466-471

Onuma, EK.; Amenta, PS. \& Jukkola, AF., et al. (2001). A phenotypic change of small intestinal epithelium to that of colonocytes in small intestinal adenomas and adenocarcinomas. Am J Gastroenterol, Vol. 96, No. 8, pp. 2480-2485

Parkin, DM.; Whelan, SL. \& Ferlay, J., et al. (1997). eds. Cancer incidence in five countries. Vol. VII, ARC Scientific Publication No. 143. Lyon: International Agency for Research on Cancer, World Health Organization and International Association of Cancer Registries

Pittenger, MF. \& Helfman, DM. (1992). In vitro and in vivo characterization of four fibroblast tropomyosins produced in bacteria: TM-2, TM-3, TM-5a, and TM-5b are co-localized in interphase fibroblasts. J Cell Biol, Vol. 118, No. 4, pp. 841-858

Rugge, M.; Correa, P. \& Dixon, MF., et al. (2000). Gastric dysplasia: The Padova international classification. Am J Surg Pathol, Vol. 24, No. 2, pp. 167-176

Sakaki, N.; Kozawa, H. \& Egawa, N., et al. (2002). Ten-year prospective follow-up study on the relationship between Helicobacter pylori infection and progression of atrophic gastritis, particularly assessed by endoscopic findings. Aliment Pharmacol Ther, Vol. 16 (Suppl 2), pp. 198-203

Sakamaki, S.; Takayanagi, N. \& Yoshizaki, N., et al. (2000). Autoantibodies against the specific epitope of human tropomyosin(s) detected by a peptide based enzyme immunoassay in sera of patients with ulcerative colitis show antibody dependent cell mediated cytotoxicity against HLA-DPw9 transfected L cells. Gut, Vol. 47, No. 2, pp. 236-241

Sanger, F.; Nicklen, S. \& Coulson, AR. (1997). DNA sequencing with chain-terminating inhibitors. Proc Natl Acad Sci USA, Vol. 74, No. 12, pp. 5463-5467

Satoh, K.; Kihira, K. \& Kawata, H., et al. (2001). p53 expression in the gastric mucosa before and after eradication of Helicobacter pylori. Helicobacter, Vol. 6, No. 1, pp. 31-36

Satoh, K.; Kimura, K. \& Takimoto, T., et al. (1998). A follow-up study of atrophic gastritis and intestinal metaplasia after eradication of Helicobacter pylori. Helicobacter, Vol. 3, No. 4, pp. 236-240

Shiao, YH.; Rugge, M. \& Correa, P., et al. (1994). p53 alteration in gastric precancerous lesions. Am J Pathol, Vol. 144, No. 3, pp. 511-517

Shiotani, A.; Iishi, H. \& Ishiguro, S., et al. (2005). Epithelial cell turnover in relation to ongoing damage of the gastric mucosa in patients with early gastric cancer: increase of cell proliferation in paramalignant lesions. J Gastroenterol 2005;40, No. 4, pp.337-344 
Sipponen, P. \& Hyvarinen, H. (1993). Role of Helicobacter pylori in the pathogenesis of gastritis, peptic ulcer and gastric cancer. Scand J Gastroenterol, Vol. 196 (suppl), pp. 3-6

Soh, K.; Yanagisawa, A. \& Hiratsuka, H., et al. (1993). Variation in K-ras codon 12 point mutation rate with histological atypia within individual colorecral tumors. Jpn J Cancer Res, Vol. 84, No. 4, pp. 388-393

Sung, JJ.; Lin, SR. \& Ching, JY., et al. (2000). Atrophy and intestinal metaplasia one year after cure of H. pylori Infection: a prospective, randomized study. Gastroenterology, Vol. 119, No. 1, pp. 7-14

Tahara E. (1993). Molecular mechanism of stomach carcinogenesis. Cancer Res Clin Oncol, Vol. 119, No. 5, pp. 265-272

Take, S.; Mizuno, M. \& Ishiki, K., et al. (2005). The effect of eradicating Helicobacter pylori on the development of gastric cancer in patients with peptic ulcer disease. Am J Gastroenterol, Vol. 100, No. 5, pp. 1037-1042

Tanaka, A.; Watari, J. \& Tanabe, H., et al. (2006). Effect of eradication of Helicobacter pylori on genetic instabilities in gastric intestinal metaplasia. Aliment Pharmacol Ther, Vol. 24 (Suppl 4), pp. 194-202

Taniguchi, M.; Geng, X. \& Glazier, KD., et al. (2001). Cellular immune response against tropomyosin isoform 5 in ulcerative colitis. Clin Immunol, Vol. 101, No. 3, pp. 289295

Tepes, B.; Kavcic, B. \& Zaletel, LK., et al. (1999). Two- to four-year histological follow-up of gastric mucosa after Helicobacter pylori eradication. J Pathol, Vol. 188, No. 1, pp. 2429

Tucci, A.; Poli, L. \& Tosetti, C., et al. (1998). Reversal of fundic atrophy after eradication of Helicobacter pylori. Am J Gastroenterol, Vol. 93, No. 9, pp. 1425-1431

Uemura, N.; Mukai, T. \& Okamoto, S., et al. (1997). Effect of Helicobacter pylori eradication on subsequent development of cancer after endoscopic resection of early gastric cancer. Cancer Epidemiol Biomarkers Prev, Vol. 6, No. 8, pp. 639-642

Uemura, N.; Okamoto, S., \& Yamamoto, S., et al. (2001). Helicobacter pylori infection and the development of gastric cancer. N Engl J Med, Vol. 345, No. 11, pp. 784-789

van der Hulst, RW.; van der Ende, A. \& Dekker, FW., et al. (1997). Effect of Helicobacter pylori eradication on gastritis in relation to cagA: a prospective 1-year follow-up study. Gastroenterology, Vol. 113, No. 1, pp. 25-30

Vogelstein, B.; Fearon, ER. \& Hamilton, SR., et al. (1988). Genetic alterations during colorectal-tumor development. $N$ Engl J Med,1988;319, No. 9, pp. 525-532

Wagner, S.; Beil, W. \& Westermann, J., et al. (1997). Regulation of gastric epithelial cell growth by Helicobacter pylori: evidence for a major role of apoptosis. Gastroenterology, Vol. 113, No. 6, pp. 1836-1847

Watari, J.; Saitoh, Y. \& Obara T., et al. (2002), Natural history of colorectal nonpolypoid adenomas: a prospective colonoscopic study and relation with cell kinetics and $\mathrm{K}$ ras mutations. Am J Gastroenterol, Vol. 97, No. 8, pp. 2109-2115

Watari, J.; Tanaka, A. \& Tanabe, H., et al. (2007). K-ras mutations and cell kinetics in Helicobacter pylori associated gastric intestinal metaplasia: a comparison before and after eradication in patients with chronic gastritis and gastric cancer. J Clin Pathol, Vol. 60, No. 8, pp. 921-926 
Watari, J.; Das, KK. \& Amenta, PS., et al. (2008). Effect of eradication of Helicobacter pylori on the histology and cellular phenotype of gastric intestinal metaplasia. Clin Gastroenterol Hepatol, Vol. 6, No. 4, pp. 409-417

Witteman, EM.; Mravunac, M. \& Becx, MJ., et al. (1995). Improvement of gastric inflammation and resolution of epithelial damage one year after eradication of Helicobacter pylori. J Clin Pathol, Vol. 48, No. 3, pp. 250-256

Wong, BC.; Lam, SK. \& Wong, WM., et al. (2004). Helicobacter pylori eradication to prevent gastric cancer in a high-risk region of China: a randomized controlled trial. JAMA, Vol. 291, No. 2, pp. 187-194

Wright, NA. (1998). Gastric carcinogenesis: when is the point of no return? In: Hunt RH, Tytgat GNJ, eds. Helicobacter pylori: Basic Mechanisms to Clinical Cure. Boston, Mass: Kluwer Academic Publishers, pp. 325-335

Wyllie, AH. (1996). The biology of cell death in tumors. Anticancer Res, Vol. 5, No. 1, pp. 131136

Yanagisawa, A.; Ohtake, K. \& Ohashi, K., et al. (1993). Frequent c-Ki-ras oncogene activation in mucous cell hyperplasias of pancreas suffering from chronic inflammation. Cancer Res, Vol. 53, No. 5, pp. 953-956

You, WC.; Brown, LM. \& Zhang, L., et al. (2006). Randomized double-blind factorial of three treatments to reduce the precancerous gastric lesion. J Natl Cancer Inst, Vol. 98, No. 14, pp. 974-983 


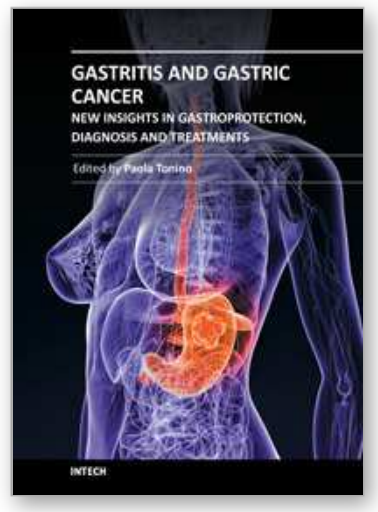

\section{Gastritis and Gastric Cancer - New Insights in Gastroprotection, Diagnosis and Treatments}

Edited by Dr. Paola Tonino

ISBN 978-953-307-375-0

Hard cover, 296 pages

Publisher InTech

Published online 15, September, 2011

Published in print edition September, 2011

This book is a comprehensive overview of invited contributions on Helicobacter pylori infection in gastritis and gastric carcinogenesis. The first part of the book covers topics related to the pathophysiology of gastric mucosal defense system and gastritis including the gastroprotective function of the mucus, the capsaicinsensitive afferent nerves and the oxidative stress pathway involved in inflammation, apoptosis and autophagy in $\mathrm{H}$. pylori related gastritis. The next chapters deal with molecular pathogenesis and treatment, which consider the role of neuroendocrine cells in gastric disease, DNA methylation in $\mathrm{H}$. pylori infection, the role of antioxidants and phytotherapy in gastric disease. The final part presents the effects of cancer risk factors associated with $\mathrm{H}$. pylori infection. These chapters discuss the serum pepsinogen test, $\mathrm{K}$-ras mutations, cell kinetics, and $\mathrm{H}$. pylori lipopolysaccharide, as well as the roles of several bacterial genes (cagA, $\operatorname{cag} \mathrm{T}$, $\operatorname{vacA}$ and dupA) as virulence factors in gastric cancer, and the gastrokine-1 protein in cancer progression.

\section{How to reference}

In order to correctly reference this scholarly work, feel free to copy and paste the following:

Jiro Watari, Hiroki Tanabe, Kentaro Moriichi, Mikihiro Fujiya, Peter S. Amenta, Hiroto Miwa, Yutaka Kohgo and Kiron M. Das (2011). Effects of Helicobacter pylori Infection on the Histology, Cellular Phenotype, K-ras Mutations, and Cell Kinetics in Gastric Intestinal Metaplasia in Patients with Chronic Gastritis and Gastric Cancer, Gastritis and Gastric Cancer - New Insights in Gastroprotection, Diagnosis and Treatments, Dr. Paola Tonino (Ed.), ISBN: 978-953-307-375-0, InTech, Available from: http://www.intechopen.com/books/gastritisand-gastric-cancer-new-insights-in-gastroprotection-diagnosis-and-treatments/effects-of-helicobacter-pyloriinfection-on-the-histology-cellular-phenotype-k-ras-mutations-and-cel

\section{INTECH}

open science | open minds

\section{InTech Europe}

University Campus STeP Ri

Slavka Krautzeka 83/A

51000 Rijeka, Croatia

Phone: +385 (51) 770447

Fax: +385 (51) 686166

www.intechopen.com

\section{InTech China}

Unit 405, Office Block, Hotel Equatorial Shanghai

No.65, Yan An Road (West), Shanghai, 200040, China

中国上海市延安西路65号上海国际贵都大饭店办公楼 405 单元

Phone: +86-21-62489820

Fax: +86-21-62489821 
(C) 2011 The Author(s). Licensee IntechOpen. This chapter is distributed under the terms of the Creative Commons Attribution-NonCommercialShareAlike-3.0 License, which permits use, distribution and reproduction for non-commercial purposes, provided the original is properly cited and derivative works building on this content are distributed under the same license. 